\title{
Lost gallstones mimicking a gastric pylorus tumour
}

\author{
Andrew KY Fung ${ }^{1}$, Beverly CB Lim ${ }^{1}$, Michael Ashcroft ${ }^{2}$, Ronald P Coggins ${ }^{3}$ \\ 1. Department of General Surgery, Aberdeen Royal Infirmary, Aberdeen, United Kingdom. 2. Department of Radiology, \\ Raigmore Hospital, Inverness, United Kingdom. 3. Department of General Surgery, Raigmore Hospital, Inverness, United \\ Kingdom.
}

Correspondence: Andrew KY Fung. Address: Department of General Surgery, Aberdeen Royal Infirmary, Aberdeen, United Kingdom. Email: andrewkaiyipfung@gmail.com

Received: March 4, 2014

DOI : $10.5430 /$ crim.v1n2p179

Online Published: June 13, 2014

URL: http://dx.doi.org/10.5430/crim.v1n2p179

\section{Abstract}

Lost gallstones after laparoscopic cholecystectomy is a frequent occurrence. We describe a case report of an unusual delayed presentation of the above condition and discuss the published literature on this topic. Prevention of gallstone spillage and retrieval of all the spilled gallstones remain the best methods of avoiding future potential morbidity.

\section{Keywords}

Lost gallstones, Gastric mass, Cholecystectomy

\section{I ntroduction}

Lost gallstones after laparoscopic cholecystectomy is a frequent occurrence. This can be a cause of significant morbidity and can present with a variety of symptoms after the index operation. Lost gallstones might be secondary to iatrogenic gallbladder perforation with intraoperative spillage of multiple gallstones that are not all subsequently retrieved. We describe a case report of an unusual delayed presentation of the above condition and discuss the published literature on this topic.

\section{Case presentation}

A seventy-six year old lady was admitted as an emergency to the local hospital in 2012 with a one-month history of colicky upper abdominal pain with intermittent non-bilious vomiting. She had no weight loss or change in bowel habit. Her past surgical history included acute gallstone pancreatitis in 2008, followed by an endoscopic retrograde cholangiopancreatography (ERCP) and sphincterotomy with interval laparoscopic cholecystectomy in 2008. She also had a diagnostic laparoscopy for non-specific abdominal pain in 2009 and a vaginal hysterectomy in 1989. The past medical history comprised hypothyroidism, ischaemic heart disease, myocardial infarction, aortic stenosis and left deep venous thrombosis.

Admission blood parameters, as well as plain abdominal and chest radiographs were unremarkable. An abdominal CT scan suggested a mass in the gastric pylorus (see Figures 1, 2). This case was discussed with a tertiary surgical unit and the advice was for an upper gastro-intestinal endoscopy (UGIE) following patient transfer. 
The subsequent UGIE was normal and the patient proceeded to diagnostic laparoscopy. There were multiple gallstones forming adhesions between the abdominal wall and matted omentum. There was no gastric pylorus mass lesion. The free gallstones were removed and a limited omentectomy with adhesiolysis was performed (see Figure 3). Her post-operative recovery was uneventful and she was discharged home two days later. A telephone follow-up 4 months later revealed that her presenting symptoms had completely resolved.
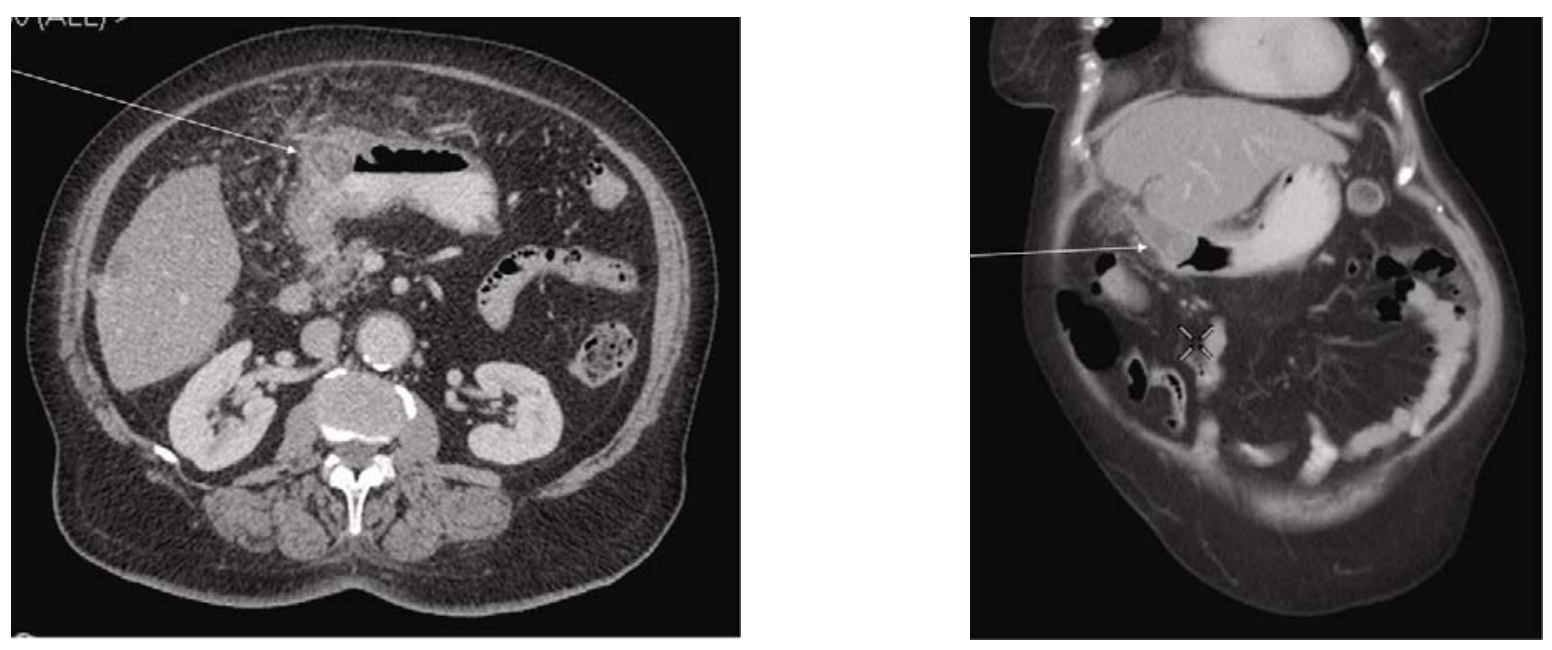

Figure 1. Laminated gallstone in gastric wall on CT (axial view).

Figure 2. Laminated gallstone and associated collection on CT (coronal view).

Figure 3. Intraoperative matted gallstones in peritoneal cavity.

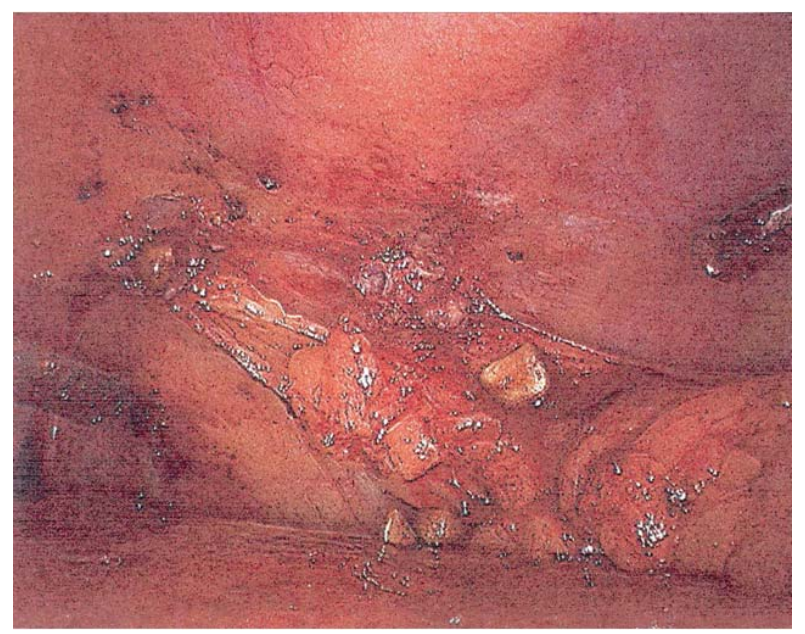

\section{Discussion}

Laparoscopic cholecystectomy has become the gold standard operative procedure for symptomatic gallstones ${ }^{[1]}$. Whilst the complications of conversion to open cholecystectomy and common bile duct injury are well described, there can be significant morbidity arising from intraoperatively lost gallstones ${ }^{[2]}$. Lost gallstones might be secondary to iatrogenic gallbladder perforation with intraoperative spillage of multiple gallstones that are not all subsequently retrieved.

Lost gallstones can present with a range of non-specific signs and symptoms ${ }^{[3]}$, including pain, abdominal swelling and fistulation, fever, weight loss, liver 'tumours' and small bowel obstruction. A literature review of the complication profile of lost gallstones after laparoscopic cholecystectomy found that the commonest reported complications were abdominal wall and intra-abdominal abscesses ${ }^{[2]}$. To the authors' best knowledge, lost gallstones mimicking a gastric pylorus tumour have not been previously reported. 
The time interval between the laparoscopic cholecystectomy and development of symptomatic lost gallstones can vary from months to years ${ }^{[4]}$. Patients might undergo multiple investigations prior to the diagnosis and definitive management. Indeed, Brockmann and colleagues ${ }^{[3]}$ stated that a mean of three diagnostic investigations were undertaken prior to re-intervention for lost gallstones. In this case study, the patient had plain radiographs, CT and UGIE prior to definitive surgical intervention.

Intraoperative spillage of bile and gallstones is associated with the formation of intra-abdominal adhesions and abscesses, as demonstrated in experimental animal models ${ }^{[5]}$. Certainly, in this patient, there were dense adhesions around the gallbladder bed at the time of re-operation which might be secondary to a foreign body inflammatory process. Woodfield and colleagues ${ }^{[6]}$ suggested the following risk factors for infective complications of spilled or lost gallstones (see Table 1).

Table 1. Risk factors for infective complications of spilled or lost gallstones ${ }^{[6]}$

\begin{tabular}{|l|}
\hline Acute cholecystitis with infected bile \\
\hline Spillage of pigment stones \\
\hline Multiple stones (>15 stones) \\
\hline Advanced age of patient \\
\hline Male gender \\
\hline
\end{tabular}

The published incidence of spilled gallstones at laparoscopic cholecystectomy can reach up to $40 \%{ }^{[3]}$. The incidence of lost gallstones, however, varied between $1.1 \%{ }^{[7]}$ and $2.3 \%{ }^{[8]}$. This might be an underestimation of the true incidence secondary to publication bias of this clinical outcome ${ }^{[3]}$. In that respect, surgeons performing laparoscopic cholecystectomy should minimise the potential for intraoperative gallstone spillage.

Prophylactic operative techniques would include the prevention of intraoperative iatrogenic gallbladder perforation, immediate retrieval of free intraperitoneal gallstones and irrigation of the abdominal cavity following spillage of gallstones. Additionally, administration of systemic intravenous antibiotics at the time of intraperitoneal contamination is recommended. Placement of the gallbladder with its stones into a retrieval bag could avoid rupture of the gallbladder during extraction through the laparoscopic port site ${ }^{[9]}$. Finally, a detailed operation note would greatly facilitate the investigation of the potential morbidities of lost gallstones.

\section{Conclusion}

Surgeons performing laparoscopic cholecystectomy need to be aware of the complications of lost gallstones. Symptomatic lost gallstones might present several years after the index operation. Informed discussion with the patient, careful operative technique and detailed documentation in the event of lost gallstones will enable more efficacious and expedient clinical diagnosis and subsequent management. However, prevention of gallstone spillage and retrieval of all the spilled gallstones remain the best methods of avoiding future potential morbidity ${ }^{[10]}$.

\section{References}

[1] Keus F, de Jong JA, Gooszen HG, van Laarhoven CJ: Laparoscopic versus open cholecystectomy for patients with symptomatic cholecystolithiasis, Cochrane Database Syst Rev. 2006; CD006231.

[2] Zehetner J, Shamiyeh A, Wayand W: Lost gallstones in laparoscopic cholecystectomy: all possible complications, American journal of surgery. 2007; 193: 73-78. http://dx.doi.org/10.1016/j.amjsurg.2006.05.015

[3] Brockmann JG, Kocher T, Senninger NJ, Schurmann GM: Complications due to gallstones lost during laparoscopic cholecystectomy, Surgical endoscopy. 2002; 16: 1226-1232. http://dx.doi.org/10.1007/s00464-001-9173-8 
[4] Casillas S, Kittur DS: Late abscess formation after spilled gallstones masquerading as a liver mass, Surgical endoscopy. 2003; 17: 833. http://dx.doi.org/10.1007/s00464-002-4266-6

[5] Agalar F, Sayek I, Agalar C, et al. Factors that may increase morbidity in a model of intra-abdominal contamination caused by gallstones lost in the peritoneal cavity, The European journal of surgery = Acta chirurgica. 1997; 163: 909-914.

[6] Woodfield JC, Rodgers M, Windsor JA: Peritoneal gallstones following laparoscopic cholecystectomy: incidence, complications, and management, Surgical endoscopy. 2004; 18: 1200-1207. http://dx.doi.org/10.1007/s00464-003-8260-4

[7] Diez J, Arozamena C, Gutierrez L, et al. Lost stones during laparoscopic cholecystectomy, HPB surgery: A world journal of hepatic, pancreatic and biliary surgery. 1998; 11: 105-108; discuss 108-109.

[8] Sarli L, Pietra N, Costi R, Grattarola M: Gallbladder perforation during laparoscopic cholecystectomy, World journal of surgery. 1999; 23: 1186-1190. http://dx.doi.org/10.1007/s002689900644

[9] McDonald MP, Munson JL, Sanders L, Tsao J, Buyske J: Consequences of lost gallstone, Surgical endoscopy. 1997; 11: 774-777. http://dx.doi.org/10.1007/s004649900449

[10] Singh K, Wang ML, Ofori E, et al. Gallstone abscess as a result of dropped gallstones during laparoscopic cholecystectomy, International journal of surgery case reports. 2012; 3: 611-613. 